
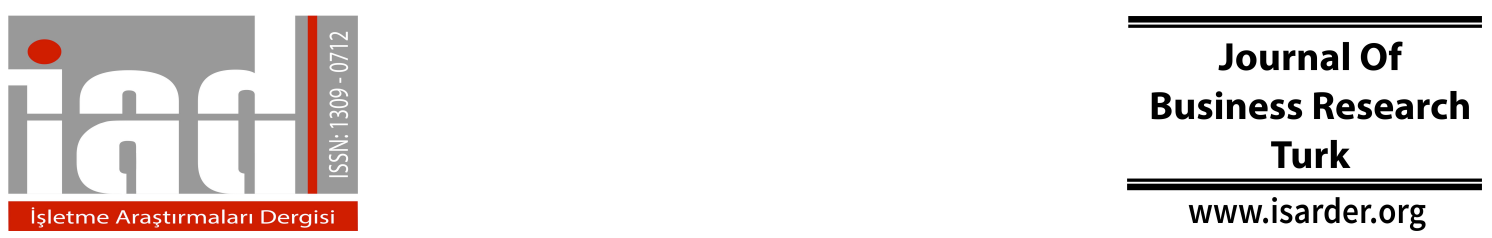

\title{
The Effect of Self-Enhancement and Regulatory Focus On Word of Mouth
}

\author{
Ezgi Akpınar \\ MEF University \\ Faculty of Economics, Administrative and Social Sciences \\ 34396 Maslak, Istanbul, Turkey \\ ezgi.akpinar@mef.edu.tr
}

\begin{abstract}
Word of mouth is one of the main drivers that shapes consumers' decisions. With the advent of social media, consumer reviews, opinions about brands propagate at a higher spread and reach masses. Thus, giving the rising interest in word of mouth, many brands are interested in understanding what makes consumers talk favorably about their products. Existing research suggests that one of the psychological motivations to engage in positive word of mouth is self-enhancement. Consumers like to provide positive information, which makes them look good to others. Yet, it is not so much known how self-enhancement affects sharing. Do consumers also provide positive recommendations when they already feel good about themselves? Our research shows that self enhancement boosts the likelihood of giving positive recommendations. Yet, this pattern does not always hold and can be moderated with regulatory focus. We show that when consumers are under high prevention focus, higher self-enhancement, in fact, decreases the likelihood of giving positive recommendations. This framework shed lights on how companies can encourage positive word of mouth, by understanding selfenhancement and regulatory focus mechanisms.
\end{abstract}

Keywords: word of mouth, regulatory focus, self-enhancement

\section{INTRODUCTION}

Consumers post reviews about restaurants, talk about new movies, or complain about a bank. Given the rise of social media, consumers live in a more connected world, where their word of mouth about products can reach masses relatively quickly and propagate to masses of consumers (Moore 2012). The consequences of word of mouth are prominent for companies (i.e., boosting sales, increasing product adoption), (see Babic et al. 2016 for a review, Chevalier and Mayzlin 2006; Godes and Mayzlin 2004; Godes and Mayzlin 2009). It is clear that word of mouth has important implications for companies, but what makes consumers talk about products and services?

Acknowledgement: I would like to thank Charlotte Bik for collecting the data during her Master thesis at Vrije University Amsterdam, the Netherlands. 
Although, there is vast amount of research that tries to understand consequences of word of mouth, there is little research that has investigated the drivers for word of mouth, in other words, what makes consumers share information about products with others. This paper aims to contribute to the emerging work on understanding the drivers of word of mouth (see Berger 2014 for a review). In particular, we investigate whether and how self-enhancement influences positive word of mouth and the moderation effect of regulatory focus.

\section{THEORETICAL FRAMEWORK}

\section{Self-enhancement}

There are various psychological motivations that drive sharing. For instance, social networking sites provide opportunities for self-presentation (Manago et al. 2008) by offering a gateway via favourable self-descriptions and photos (Buffardi and Cambell 2008). People engage in self-enhancing concerns (Chambers and Windschitl 2004; Schlosser 2011) to give others a positive impression about themselves (Vohs, Baumeister and Ciarocco 2005). People generate positive WOM of their own experiences due to self-enhancement motives (De Angelis et al. 2012). Providing positive news, interesting videos, exciting photos would make consumers look good to others (Buechel and Berger 2015), which provides self-enhancement. While it is clear from literature that word of mouth could result in higher self-enhancement, could it be that consumers with already high self-enhancement generate more positive word of mouth? Self-enhancement is about achieving, and maximizing positive self-view. When consumers have a better view of themselves, they might be more confident and positive about their own consumption experiences, and therefore would be more willing to share their experiences with others. Further, there is initial evidence in literature that suggests that positive emotions such as happiness (i.e. high arousal emotion), makes consumers more likely to share (Berger 2011). Taken together, we expect that self-enhancement should boost positive word of mouth. More formally stated:

H1: Higher self-enhancement will increase the likelihood of sharing positive word of mouth.

\section{Regulatory focus}

Self-enhancement might be achieved through dispositional or individual differences such as regulatory focus. Regulatory focus proposes two main orientations: promotion promotion and prevention focus. Whereas promotion focus is often being more sensitive to positive outcomes, prevention focus is more sensitive to negative outcomes (Aaker and Lee 2001). Research suggests that self-enhancement is positively related to promotion focus (Hepper, Gramzow and Sedikides 2010). Then, one could expect that similar to self-enhancement, promotion focus might increase sharing positive word of mouth. Because existing research already suggests the link between self-enhancement and promotion focus, we will not make a formal hypothesis but aim to replicate the link between self-enhancement and promotion focus, and further test their effects on word of mouth. If promotion focus also boosts positive word of mouth, then self-enhancement and promotion focus can be used interchangeably to increase positive word of mouth.

While we predict that the effect of self-enhancement and promotion focus are correlated, we do not expect this correlation between self-enhancement and prevention 
focus. In fact, we predict that prevention focus might create a boundary condition for the positive effect of self-enhancement. Prevention focus individuals often perceive their goals as duties and obligations, and focus on the negative outcomes, thus we expect that despite high self-enhancement, they will not be willing to share positive word of mouth. More formally stated, we hypothesize that:

H2: Prevention focus will moderate the effect of self-enhancement on positive word of mouth:

H2a: Under low prevention focus, higher self-enhancement will increase the likelihood of sharing positive word of mouth.

$\mathrm{H} 2 \mathrm{~b}$ : Under high prevention focus, higher self-enhancement will not increase the likelihood of sharing positive word of mouth.

\section{CURRENT RESEARCH}

There has been extensive research on the effect of self-enhancement and regulation focus in relation to various cognitive and social behaviors (Leonardelli et al. 2007; Liberman et al. 2001; Semin et al. 2005; Chung and Tsai 2009). However, there has not been much research on understanding the effect of both self-enhancement and regulation focus on word of mouth, either separately or combined. In this research, we will investigate the effect of self-enhancement on word of mouth and the moderation effect of regulatory focus. By understanding the drivers of word of mouth, marketers will be able to benefit from their consumers that have favourable opinions about their products or services through their positive recommendations. In this paper, we will test our predictions through a behavioural experiment. In this experiment we manipulated self-enhancement, and measured regulatory focus of the participants, and then tested their willingness to share positive recommendation imagining a positive consumption experience.

\section{BEHAVIORAL EXPERIMENT}

We conducted a behavioral experiment where we manipulate self-enhancement, measure regulatory focus and examine sharing positive recommendations. We test whether (a) higher self enhancement boosts giving positive recommendations, and (b) regulatory focus (prevention vs. promotion focus) moderates the effect of giving positive recommendations.

\section{Method}

Procedure. One hundred twenty-three respondents (49,2\% female, 50,8\% male) participated in an online experiment. Respondents ranged in age from 19 to 65 years $(\mathrm{M}=35, \mathrm{SD}=11,77)$. The respondents were recruited via an online panel, where they were asked to participate in an online experiment in return for monetary payment.

Participants were randomly assigned to one of the two conditions (selfenhancement vs. control) and completed a variety of measures including regulatory focus measure and our main dependent measure (likelihood of giving positive recommendation).

First, in order to manipulate self-enhancement, participants wrote a brief paragraph where they were asked to describe an academic success (adapted from Hepper, Gramzow and Sedikides 2010 and De Angelis et al. 2012). In the control condition, participants wrote a brief paragraph where they were asked to write about 
their last trip to the library. In order to make sure the manipulation worked as intended, and participants' had in fact higher level of self-enhancement in the condition compared to control condition, participants were asked to complete a self-view scale with six items, on a seven-point scale ( $1=$ 'unsatisfied with yourself', 'not proud of yourself', 'bad about yourself', 'unsuccessful', 'not confident about yourself', and 'worthless'; 7'satisfied with yourself', proud of yourself', 'good about yourself', 'successful', 'confident about yourself', and 'a person of worth').

After the manipulation, participants were instructed to imagine that they had a shopping experience at a shop, which went quite positive. Considering this experience, they were asked their likelihood of giving positive recommendation about this shop, using 4 items on 7 point Likert scale (1= strongly agree to strongly disagree), which was adapted from Srinivasan et al., 2002, using the items such as 'I would say positive things about this shop to other people'; 'I recommend this shop to anyone who seeks my advise'; 'I do not encourage friends to do shopping at this shop (reversed)'; 'I hesitate to refer my acquaintances/friends to shop there (reversed)'.

Finally, participants' regulatory focus was measured using 18 scale items, nine of the items measuring prevention focus and nine of the items measuring promotion focus, which was adapted from Zhao and Pechmann (2007), see the full list of items in Appendix. The items for prevention focus are intended to measure the degree to which a person is worried about being irresponsible and is motivated to avoid failure, losses, and threats $($ Cronbach alpha $=.72)$. The items for promotion focus are intended to measure the degree to which a person is motivated by achievement and focused on opportunities for advancement (Cronbach alpha $=.77)$.

\section{RESULTS}

Manipulation check. First, we checked the effectiveness of the manipulation. The manipulation check showed that participants in the self-enhancement condition held a more positive self-view $(\mathrm{M}=6.01, \mathrm{SD}=1.34)$, than those in the control condition $(\mathrm{M}=5.29, \mathrm{SD}=1.01, \mathrm{~F}(1,121)=11.21, p<0.05)$. This validates that the manipulation was successful.

Self-enhancement on recommendation. Second, we examined how selfenhancement influenced providing positive recommendation. As predicted, selfenhancement is positively related to providing positive recommendations ( $\beta$ self-enhancement $=.12, \mathrm{SE}=.06 ; \mathrm{F}(1,121)=4.08, p=0.045)$. This empirical evidence provides support for our first hypothesis $\mathrm{H} 1$.

Regulatory focus on recommendation. Although, it is not our main theoretical test, we tested the effect of promotion and prevention focus on providing positive recommendation. To avoid potential multi-collinearity (due to the high correlation between promotion and prevention focus, $\mathrm{r}=.82, \mathrm{p}<.001$ ), we separately examined the effect of each continuous predictor on recommendation. Both promotion focus and prevention focus did not have a significant effect on providing positive recommendation $\left(\beta_{\text {promotion }}=.09, \mathrm{SE}=.06 ; \mathrm{F}(1,121)=2.22, p=.13 ; \beta_{\text {prevention }}=.01, \mathrm{SE}=.06 ; \mathrm{F}(1,121)\right.$ $=.042, p=.83)$.

Self-enhancement and regulatory focus on recommendation. Consistent with our expectations, while the correlation between promotion focus and self-enhancement was significant, yet quite low $(\mathrm{r}=.19, \mathrm{p}<.05)$, the correlation between prevention focus and 
self-enhancement was not significant $(\mathrm{r}=.10, \mathrm{p}>.05)$. To avoid potential multicollinearity (due to correlation between promotion focus and self-enhancement), we only examined the moderation of prevention focus on the effect of self-enhancement on providing positive recommendation. The interaction between self-enhancement and prevention focus was significant and negative $(\beta$ self-enhance* prevention $=-1.14, \mathrm{SE}=.04, \mathrm{t}=$ $1.93, p<.05)$. This result support our hypothesis $\mathrm{H} 2$, which predicted that higher selfenhancement moderates the positive effect of self-enhancement on positive word of mouth.

As seen in Figure 1, while under low prevention focus, higher self-enhancement boosts positive recommendations (supporting H2a), under high prevention focus, the effect of self-enhancement on positive recommendations disappears (supporting $\mathrm{H} 2 \mathrm{~b}$ ). Looked from another way, under low self-enhancement, higher prevention focus increases positive recommendations, but under high self-enhancement, higher prevention focus decreases positive recommendations.

Taken together, these results support our hypotheses. First, we have shown empirical evidence that supports $\mathrm{H} 1$, which predicts that higher self-enhancement increases the likelihood of sharing positive word of mouth. Second, we have provided support for $\mathrm{H} 2$, which predicts that prevention focus moderates the effect of selfenhancement on positive word of mouth. Particularly, our results empirical evidence supporting $\mathrm{H} 2 \mathrm{a}$ and $\mathrm{H} 2 \mathrm{~b}$ respectively, and demonstrated that under low prevention focus, higher self-enhancement increases the likelihood of sharing positive word of mouth $(\mathrm{H} 2 \mathrm{a})$ and under high prevention focus, higher self-enhancement does not increase the likelihood of sharing positive word of mouth $(\mathrm{H} 2 \mathrm{~b})$.

\section{Figure 1: Prevention Focus Moderates the Effect of Self-Enhancement}

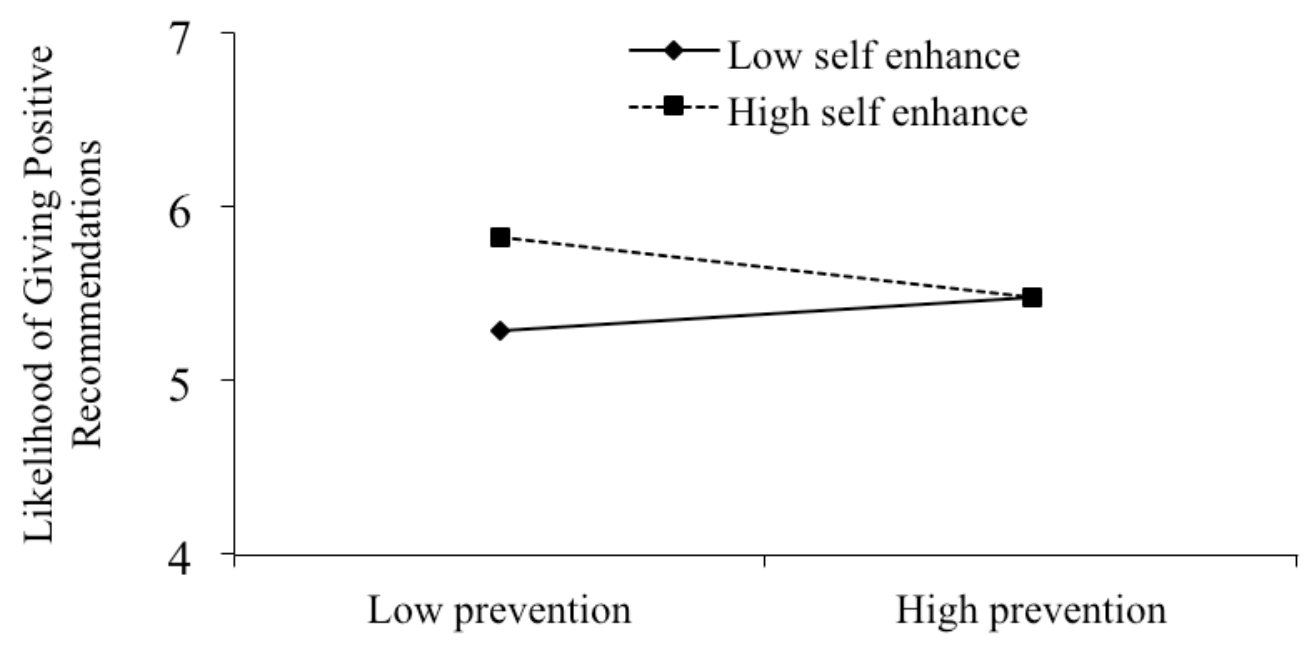

\section{Discussion}

Using manipulations of self-enhancement and measures of regulatory focus, this study underscores our theorizing. While self-enhancement increased positive recommendations, regulatory focus (prevention and promotion focus) did not have a significant effect. The regulatory focus (prevention focus), however, moderates the 
effect of self-enhancement. While for consumers with low prevention focus, boosting their self-enhancement, would make them share more positive recommendations, for consumers with high prevention focus, boosting self-enhancement would not boost positive recommendations. Although, literature suggests that self-enhancement would increase positive word of mouth, and we have provided supporting evidence for this, we have also shown a boundary condition for the effect self-enhancement, showing that under high prevention focus, the positive effect of self-enhancement on positive recommendations disappears.

Note that we did not explore the moderating effect of promotion focus on the effect of self-enhancement any further, as we have shown that self-enhancement is positively correlated with promotion focus, and would be biased due to multicollinearity. This is an initial evidence that promotion focus and self-enhancement can be used as compensatory mechanisms to boost positive word of mouth.

\section{GENERAL DISCUSSION}

Both academics and practitioners have become increasingly interested in word of mouth. Given that investing in word of mouth is a much more cost-efficient way to advertise products, more marketers are trying to achieve positive recommendations from their customers. While it is clear that achieving positive word of mouth is important, less is known about what makes consumers share positive recommendations.

A laboratory experiment demonstrated how self-enhancement and regulation focus (promotion vs. prevention focus) shapes sharing positive recommendations. In particular, we show that self-enhancement boosts sharing positive recommendations. Although we have shown that self-enhancement and promotion focus are correlated, promotion focus was not able to boost positive recommendations. While marketers can benefit from higher levels of self-enhancement to achieve more positive recommendations, they should be precautious about consumers' regulatory focus. Prevention focused consumers would be reluctant to share positive recommendations despite their high levels of self-enhancement. But under low prevention focus, higher self-enhancement would make consumers more likely to provide positive word of mouth.

Taken together, the findings demonstrate that self-enhancement generate more positive recommendations, and it should be under low prevention focus. Using a tight laboratory experiment allows us to rigorously test the causality and control for a variety of several factors that would affect sharing.

\section{CONTRIBUTIONS AND IMPLICATIONS}

These findings make several contributions. First, we integrate work on selfenhancement and regulatory focus, shedding light on what makes consumers share positive recommendations. Second, we deepen understanding around drivers of word of mouth. While some work suggests that self-enhancement is a consequence for sharing (Buechel and Berger 2015), we demonstrate that it might be also a driver for sharing positive recommendations about products or services. Further, while self-enhancement and regulatory focus have been extensively studied in marketing literature, it has received less attention in understanding drivers of word of mouth. We demonstrate whether and how self-enhancement and regulatory focus can be beneficial to boost positive recommendations. 
The results also have important marketing implications, providing useful insights to receive more positive recommendations, assuming that consumers had a pleasant experience. There are many websites (e.g. Booking.com, TripAdvisor), where consumers are requested to provide feedback after their consumption experiences. Our results suggest that making the consumers self-enhance in a positive way (i.e. some positive images or background music might be used) should make them provide more positive recommendations.

Making the consumers feel self-enhanced might boost favorable recommendations, yet marketers should be precautious. We have showed that the positive effect of self-enhancement on sharing is bound to low prevention focused consumers, and this effect might not be prevalent for high prevention focused consumers.

Overall, our work deepens understanding about why people share positive recommendations and sheds light on how managers can make their customers provide positive recommendations through customers' self-enhancement and regulatory focus.

\section{LIMITATIONS AND FURTHER RESEARCH}

This work comes limitations, which offers new areas for future research.

We conducted an experiment to demonstrate causality and rule out alternative explanations for our results. But this has limitations. For instance, we used reported willingness to share, which is not actual sharing. Using reported willingness to share is a common method in word of mouth literature (Akpinar and Berger 2016, Barasch and Berger 2014), and correlated with actual shares. Further studies should measure actual sharing, in order to provide external validity.

This work offers several interesting questions for future research. Research might examine how self-enhancement affects shares in a more detailed way. Our evidence suggests that self-enhancement boost positive recommendations. But could it be that self-enhancement hurts negative recommendations? One might imagine that selfenhancement might make consumers share less negative information. Future research should examine the effect of self-enhancement on various measures of word of mouth with different valence.

Research could also examine different ways to boost self-view and how it affects word of mouth. While some people self-enhance themselves to feel positive, some other people self-protect to feel positive. Might self-enhancement boost positive word of mouth and self-protection boost negative word of mouth? Future research could examine how different ways to feel positive influence word of mouth?

It would also be interesting to more deeply examine the relationship between our findings on word of mouth and traditional advertising tools such as TV ads. Could it be that consumers would evaluate TV ads more favorably when they feel higher selfenhanced and this effect is bound to low prevention focused consumers. Further research could extend our findings into different domains.

Finally, it would also be interesting to consider how word of mouth drivers may vary based on whether consumers are talking about their own consumption experiences or other people's experiences. When consumers express their own experiences, they might be more willing to see themselves in a positive light and self-enhancement might 
be more effective. On the other hand, when consumers tell about some other consumers' experiences, the role of self-enhancement might be weaker. Further, when consumers narrate their own experiences, we have shown that prevention focus creates a boundary condition. Future research could examine whether sharing some other people's experiences might be less affected by prevention focus?

In conclusion, this research illustrates how self-enhancement and regulatory focus shape positive recommendations. We shed light on how these two components influence providing positive recommendations and provide insights for marketers.

\section{REFERENCES}

Aaker, J. L. and Lee, A. L. (2001), “'I' Seek Pleasures and 'We' Avoid Pains: The Role of Self-Regulatory Goals in Information Processing and Persuasion”, Journal of Consumer Research, 28 (June), 33-49.

Akpinar, E, and Berger, J. (2016), "Valuable Virality", Journal of Marketing Research forthcoming.

Barasch A, and Berger J. (2014), "Broadcasting and Narrowcasting: How Audience Size Affects What People Share", Journal of Marketing Research 5: 286 - 299.

Babić, A., Sotgiu F., Valck K., and Bijmolt T.H.A. (2016), "The Effect of Electronic Word of Mouth on Sales: A Meta-Analytic Review of Platform, Product, and Metric Factors", Journal of Marketing Research, forthcoming.

Berger, J. (2011), "Arousal Increases Social Transmission of Information", Psychological Science, 22(7), 891-893.

(2014), "Word of Mouth and Interpersonal Communication: A Review and Directions for Future Research", Journal of Consumer Psychology, 24(4), 586607.

Buechel, E. C. and Berger J. (2015). "Motivations for Engaging in Social Media", In Claudiu Dimofte, Curtis Haugtvedt and Richard Yalch (Eds.), Consumer Psychology in a Social Media World.

Buffardi, L. E., and Campbell, W. K. (2008). "Narcissism and Social Networking Web Sites", Personality and Social Psychology Bulletin, 34(10), 1303-1314.

Chambers, J. R., and Windschitl, P. D. (2004). "Biases in Social Comparative Judgments: The Role of Non-Motivated Factors in Above-Average And Comparative-Optimism Effects", Psychological Bulletin, 130(5), 813.

Chevalier, J. A., and Mayzlin, D. (2006). "The Effect of Word of Mouth On Sales: Online Book Reviews", Journal of Marketing Research, 43(3), 345-354.

Chung, C. M.Y., and Tsai, Q. (2009). "The Effects of Regulatory Focus and Tie Strength on Word-of-mouth Behaviour", Asia Pacific Journal of Marketing and Logistics, 21(3), 329 - 341 
De Angelis, M., Bonezzi A., Peluso A. M., Rucker D. D., and Costabile M. (2012), “On Braggarts and Gossips: A Self-Enhancement Account of Word-of-Mouth Generation and Transmission", Journal of Marketing Research, 49(4), 551-563.

Godes, D., and Mayzlin, D. (2004). "Using Online Conversations to Study Word-OfMouth Communication”, Marketing Science, 23(4), 545-560.

Godes D, and Mayzlin D. (2009). "Firm-Created Word-Of-Mouth Communication: Evidence from A Field Test", Marketing Science, 28 (4), 721-739.

Hepper, E. G., Gramzow, R. H., and Sedikides, C. (2010). "Individual Differences in Self-Enhancement and Self-Protection Strategies: An Integrative Analysis", Journal of Personality, 78(2), 781-814.

Leonardelli, G., Lakin, J.L. and Arkin, R.M. (2007), "A Regulatory Focus Model of Self-Evaluation," Journal of Experimental Social Psychology, 43, 1002-9.

Liberman, N., Molden, D. C., Idson, L. C., and Higgins, E. T. (2001), "Promotion and Prevention Focus on Alternative Hypotheses: Implications for Attributional Functions", Journal of Personality and Social Psychology, 80(1), 5-18.

Manago, A. M., Graham, M. B., Greenfield, P. M., and Salimkhan, G. (2008). "SelfPresentation and Gender on MySpace", Journal of Applied Developmental Psychology, 29(6), 446-458.

Moore, S. G. (2012). "Some Things Are Better Left Unsaid: How Word of Mouth Influences the Storyteller", Journal of Consumer Research, 38(6), 1140-1154.

Schlosser, A. E. (2011). "Can Including Pros and Cons Increase the Helpfulness and Persuasiveness of Online Reviews? The Interactive Effects of Ratings and Arguments", Journal of Consumer Psychology, 21(3), 226-239.

Semin, G. R., Higgins, T., de Montes, L. G., Estourget, Y., and Valencia, J. F. (2005). "Linguistic Signatures of Regulatory Focus: How Abstraction Fits Promotion More Than Prevention”, Journal of Personality and Social Psychology, 89(1), 36.

Srinivasan, S. S., Anderson, R., and Ponnavolu, K. (2002). "Customer Loyalty in ECommerce: An Exploration of Its Antecedents and Consequences", Journal of Retailing, 78(1), 41-50.

Vohs, K. D., Baumeister, R. F., and Ciarocco, N. J. (2005). "Self-Regulation and SelfPresentation: Regulatory Resource Depletion Impairs Impression Management and Effortful Self-Presentation Depletes Regulatory Resources", Journal of Personality and Social Psychology, 88(4), 632.

Zhao, G., and Pechmann, C. (2007). “The Impact of Regulatory Focus On Adolescents' Response to Antismoking Advertising Campaigns", Journal of Marketing Research, 44(4), 671-687. 


\section{Appendix: The effect of self-enhancement ad regulatory focus on word of mouth}

\section{Scale items used to measure regulatory focus}

\section{Prevention focus:}

1. I am anxious that I will fall short of my responsibilities and obligations.

2. I often think about the person I am afraid I might become in the future.

3. I often worry that I will fail to accomplish my academic goals.

4. I see myself as someone who is primarily striving to become the self I 'ought' to be- to fulfil my duties, responsibilities, and obligations.

5. I often imagine myself experiencing bad things that I fear might happen to me.

6. I frequently think about how I can prevent failures in my life.

7. I am more orientated toward preventing losses than I am toward achieving gains.

8. My major goal in school right now is to avoid becoming an academic failure

9. In general, I am focused on preventing negative events in my life.

\section{Promotion focus:}

1. I frequently imagine how I will achieve my hopes and aspirations.

2. I often think about the person I would ideally like to be in the future.

3. I typically focus on the success I hope to achieve in the future.

4. My major goal in school right now is to achieve my academic ambitions.

5. I see myself as someone who is primarily striving to reach my 'ideal self' - to fulfil my hopes, wishes, and aspirations.

6. I often think about how I will achieve academic success.

7. In general, I am focused on achieving positive outcomes in my life.

8. I often imagine myself experiencing good things that I hope will happen to me.

9. Overall, I am more orientated toward achieving success than preventing failure. 